Original paper

\title{
Normalizing serum hepcidin but not $\alpha$-1-antitrypsin level during effective treatment of chronic hepatitis C
}

\author{
Magdalena Rogalska-Taranta', Jerzy Jaroszewicz ${ }^{1,2}$, Robert Flisiak \\ 'Department of Infectious Diseases and Hepatology, Medical University of Bialystok, Bialystok, Poland \\ 2Department of Infectious Diseases and Hepatology, Medical University of Silesia, Bytom, Poland
}

\begin{abstract}
Aim of the study: We investigated the impact of pegylated interferon $\alpha$-2 in combination with ribavirin (PEGIFN $\alpha /$ RBV) treatment on hepcidin and $\alpha-1$-antitrypsin concentrations in the serum of patients with chronic hepatitis C.

Material and methods: We measured serum concentrations of hepcidin, prohepcidin and $\alpha-1$-antitrypsin by enzyme-linked immunosorbent assays in patients with chronic hepatitis $\mathrm{C}$ before and during antiviral therapy.

Results: Hepcidin concentrations were increased in both genotype $1 \mathrm{~b}$ and $3 a$ hepatitis $\mathrm{C}$ virus (HCV) infected patients as compared with the control group. During treatment of patients infected with genotype $1 \mathrm{~b} \mathrm{HCV}$ hepcidin levels gradually declined, reaching significantly lower values at the treatment termination than before therapy. Treatment responders showed an increased concentration of hepcidin at week 4 of therapy and a subsequent decrease to values significantly lower than observed among non-responders at week 48 of treatment. $\alpha-1$-antitrypsin concentration was not affected by the treatment efficacy.

Conclusions: Successful therapy of patients persistently infected with HCV was associated with restoration of serum hepcidin concentration to values similar to the control group. Differential dynamics of hepcidin during PEG-IFN $\alpha / R B V$ therapy in responders and non-responders might indicate the direct influence of viral eradication on iron homeostasis.
\end{abstract}

Key words: chronic hepatitis C, iron homeostasis, hepcidin, prohepcidin, $\alpha-1$-antitrypsin.

\section{Address for correspondence}

Dr. Magdalena Rogalska-Taranta, Department of Infectious Diseases and Hepatology, Medical University of Bialystok, 14 Zurawia St., 15-540 Bialystok, Poland, phone: +48 606138 661, e-mail: magdalena.rogalska@umb.edu.pl

\section{Introduction}

Iron overload was shown to be common among patients with chronic hepatitis $\mathrm{C}(\mathrm{CHC})$ and to correlate with a poor response to antiviral therapy [1-3]. Iron is an essential element for all living organisms required in wide range of metabolic processes including DNA synthesis, oxygen transport, and energy production. However, its excess is harmful to the organism by evoking reactive oxygen species and inflammatory cytokines, leading to liver fibrosis and hepatic carcinogenesis, and thus must be thoroughly controlled $[4,5]$. The key iron regulatory hormone is hepcidin, an antimicrobial peptide synthesized by hepatocytes and se- creted into the blood [6, 7]. Hepcidin plays a key role as a hormone regulating iron absorption and release from resources accumulated in macrophages. In the case of increased iron demand, in iron deficiency in anemia and hypoxia, hepcidin synthesis decreases to provide increased intestinal absorption of the iron and its mobilization from macrophages of the reticuloendothelial system. On the other hand, experimentally induced inflammation results in increased expression of hepcidin, which is associated with anemia [8]. Decreased production of hepcidin causes excessive uptake and intracellular accumulation of iron in the body, especially in the parenchymal organs, including the liver [7, 9]. Hepcidin is synthesized in the liver as an 84-amino 
acid (aa) preprohormone $[6,10]$, targeted to the secretory pathway, and cleaved into a 25 -aa mature peptide by furin [11]. In our previous study a significant reduction of serum prohepcidin levels was observed in patients with chronic hepatitis $\mathrm{C}$ who achieved a sustained virological response (SVR) as a result of therapy with pegylated interferon $\alpha-2$ (PEG-IFN $\alpha$ ) in combination with ribavirin (RBV) [12]. The studies in vitro and in vivo showed that an inhibitor of serine proteases, $\alpha-1$-antitrypsin, binds preprohepcidin and prohepcidin but not hepcidin intracellularly and in the plasma. $\alpha$-1-antitrypsin by binding to prohepcidin can protect it from proteolytic activity of convertases involved in the transformation of the propeptide to hepcidin [13]. It was shown recently that hepcidin gene (HAMP) expression is upregulated in cell culture early after induction by IFN- $\alpha$ [14]. Therefore, we investigated whether PEG-IFN $\alpha$ plus RBV treatment has an impact on hepcidin and $\alpha-1$-antitrypsin concentrations in the serum of patients with CHC. A further aim of this study was to determine whether changes in hepcidin and prohepcidin concentrations in patients with chronic hepatitis $\mathrm{C}$ virus (HCV) infection are due to iron metabolism disorder or $\alpha$-1-antitrypsin level or are secondarily related to the persistent $\mathrm{HCV}$ infection.

\section{Material and methods}

Hepcidin and $\alpha$-1-antitrypsin concentrations were measured in the sera of 40 patients with $\mathrm{CHC}$ before and during standard PEG-IFNa/RBV combination antiviral therapy and correlated with prohepcidin level, studied by our group previously [12]. Clinical characteristics of the studied population are presented in Table 1 . As a control, hepcidin, prohepcidin and $\alpha$-1-antitrypsin concentrations were measured in 15 healthy volunteers (anti-HCV negative; 7 females and 8 males, median age: 40 years). Concentration measurements were performed by enzyme-linked immunosorbent assays: human Hepcidin-25 (EIA Extraction-free kit; Bachem, Germany), pro-hepcidin ELISA (DRG Instrument $\mathrm{GmbH}$, Marburg, Germany) and the $\alpha-1$-antitrypsin ELISA Clearance (Immundiagnostik, Germany). Concentration of studied proteins was determined prior to treatment, and then during the antiviral therapy in weeks 4, 12, 24 and 48 (genotype 1). Patients were divided into two groups: responders (R), defined as undetectable HCV-RNA at week 24 after the end of therapy, and non-responders (NR), defined as HCV-RNA positive at week 24 after the end of therapy. Results were analyzed in relation to the therapy efficacy, liver function and inflammatory-necrotic process markers, HCV RNA concentration, virus genotype, and iron metabolism. The level of HCV RNA was determined by TaqMan Real-Time PCR with a detection limit of $50 \mathrm{IU} / \mathrm{ml}$.

The study was conducted with the prior approval of the Ethical Committee of the Medical University of Bialystok according to the ethical guidelines of the Declaration of Helsinki. Informed consent was obtained from all patients enrolled in the study. The values of analyzed parameters are presented as the mean and standard error of the mean or median with minimum and maximum. Statistical significance of differences was calculated using Student's $t$ test or the Mann-Whitney $U$ test, where appropriate. In the case of dependent variables with non-Gaussian distribution, statistical differences were compared using the Wilcoxon signed-rank test. Correlations were performed using Pearson's correlation or the Spearman rank method, where appropriate. Data analysis was performed using Statistica 8.0. Calculated values of $p<0.05$ were considered as significant.

\section{Results}

As shown in Table 1 male gender dominated in the study. Age of patients was similar in each group, but was significantly lower in the responders group of CHC patients infected with genotype $3 \mathrm{a}$. This can be however attributed to the small sample size $(n=3)$ of the group. Baseline HCV RNA level was significantly higher in subjects infected with genotype $1 \mathrm{~b}$ than $3 \mathrm{a}$, although differences dependent on subsequent treatment efficacy were not observed. The values of the analyzed markers of liver function and iron metabolism did not show statistically significant differences (Table 1).

Hepcidin concentrations measured in all patients before treatment were significantly higher than values obtained in the control group $(221.4 \pm 24.7 \mathrm{ng} / \mathrm{ml}$ vs. $55.7 \pm 9.6 \mathrm{ng} / \mathrm{ml}, p<0.001)$. Also, the values were increased in both genotype $1 \mathrm{~b}(240 \pm 34 \mathrm{ng} / \mathrm{ml}$ vs. $55.7 \pm 9.6 \mathrm{ng} / \mathrm{ml}, p<0.001)$ and genotype $3 \mathrm{a}(193.2$ $\pm 35.2 \mathrm{ng} / \mathrm{ml}$ vs. $55.7 \pm 9.6 \mathrm{ng} / \mathrm{ml}, p<0.001)$ infected patients in comparison to the control group. However, no significant differences in baseline hepcidin concentration in relation to treatment efficacy were observed (Table 2). The baseline $\alpha$-1-antitrypsin concentrations did not differ significantly from control values, with the exception of genotype $3 \mathrm{a} \mathrm{CHC}$, where the concentration was significantly higher in the NR group. However, the limitation was that there were only 3 cases in the group (Table 2).

During treatment of genotype $1 \mathrm{~b} \mathrm{HCV}$ infected patients hepcidin levels gradually declined, reaching a value of $69 \pm 19 \mathrm{ng} / \mathrm{ml}$ at the treatment termination, 
Table 1. Baseline (before treatment) characteristics of the study cohort, including hepatitis C virus (HCV) genotype and response (R) or non-response (NR) to antiviral therapy. Values given as mean $\pm \mathrm{SE}$

\begin{tabular}{|c|c|c|c|c|c|c|}
\hline \multirow[t]{2}{*}{ Factor } & \multicolumn{2}{|c|}{ Genotype $1 b, n=29$} & \multicolumn{2}{|c|}{ Genotype 3a, $n=24$} & \multicolumn{2}{|c|}{ All patients, $n=53$} \\
\hline & $\mathrm{NR}, n=16$ & $\mathrm{R}, n=13$ & $\mathrm{NR}, n=3$ & $\mathrm{R}, n=21$ & $\mathrm{NR}, n=19$ & $\mathrm{R}, n=34$ \\
\hline Age (years) (median, min.-max.) & $48(23-58)$ & $47(21-67)$ & $24(20-26)$ & $47(25-64)^{\#}$ & $44(20-58)$ & $47(21-67)$ \\
\hline Gender, $n$ (M/F) & $13 / 3$ & $11 / 2$ & $2 / 1$ & $12 / 9$ & $15 / 4$ & $23 / 11$ \\
\hline HCV RNA log10 (IU/ml) & $4.1 \pm 0.3$ & $4.5 \pm 0.4$ & $2.4 \pm 0.1$ & $2.6 \pm 0.2$ & $3.8 \pm 0.3$ & $3.4 \pm 0.3$ \\
\hline ALT (U/I) & $75.1 \pm 8.7^{*}$ & $110 \pm 29$ & $133 \pm 26^{*}$ & $112 \pm 24$ & $84.3 \pm 9.5$ & $111 \pm 18$ \\
\hline Bilirubin (mg/dl) & $1.2 \pm 0.1$ & $1.1 \pm 0.2$ & $1.1 \pm 0.0$ & $1.0 \pm 0.1$ & $1.2 \pm 0.1$ & $1 \pm 0.1$ \\
\hline $\mathrm{Fe}(\mu \mathrm{g} / \mathrm{dl})$ & $162 \pm 20$ & $139 \pm 18$ & $165 \pm 29$ & $127 \pm 11$ & $163 \pm 18$ & $131 \pm 9$ \\
\hline $\mathrm{TIBC}(\mu \mathrm{g} / \mathrm{dl})$ & $317 \pm 21$ & $352 \pm 21$ & $361 \pm 25$ & $346 \pm 14$ & $324 \pm 18$ & $348 \pm 11$ \\
\hline $\mathrm{UIBC}(\mu \mathrm{g} / \mathrm{dl})$ & $172 \pm 45$ & $203 \pm 55$ & $218 \pm 51$ & $135 \pm 21$ & $171 \pm 35$ & $160 \pm 25$ \\
\hline Ferritin (ng/ml) & $205 \pm 35$ & $255 \pm 50$ & $135 \pm 62$ & $193 \pm 58$ & $196 \pm 32$ & $217 \pm 41$ \\
\hline Hemoglobin (g/dl) & $14.5 \pm 0.4$ & $15.0 \pm 0.3$ & $15.4 \pm 0.9$ & $14.7 \pm 0.3$ & $14.6 \pm 0.4$ & $14.8 \pm 0.2$ \\
\hline
\end{tabular}

*Statistically significant $(p<0.05)$ differences between genotype $1 b$ and $3 a$ (comparing NR vs. NR and $R$ vs. $R$ )

"Statistically significant differences between NR and $R$ in the genotype.

Table 2. Baseline hepcidin, prohepcidin [10] and $\alpha-1$-antitrypsin concentrations in relation to the control group values, depending on response (R) or nonresponse (NR) to treatment. Values given as mean $\pm \mathrm{SE}$

\begin{tabular}{lccccccc}
\hline \multirow{2}{*}{ Factor } & Control group & \multicolumn{2}{c}{ Genotype 1b } & \multicolumn{2}{c}{ Genotype 3a } & \multicolumn{2}{c}{ All patients } \\
\cline { 2 - 7 } & & NR & R & NR & R & NR & R \\
\hline Hepcidin $(\mathrm{ng} / \mathrm{ml})$ & $55.7 \pm 9.6$ & $219 \pm 37^{*}$ & $261 \pm 58^{*}$ & $129 \pm 42$ & $208 \pm 42^{*}$ & $201 \pm 31^{*}$ & $234 \pm 35^{*}$ \\
\hline Prohepcidin $(\mathrm{ng} / \mathrm{ml})$ & $84.1 \pm 7.8$ & $88.3 \pm 11.5$ & $88.9 \pm 14.7$ & $94.1 \pm 8.0$ & $99.5 \pm 5.2$ & $89.2 \pm 9.7$ & $85.4 \pm 6.4$ \\
\hline$\alpha$-1-antitrypsin $(\mathrm{mg} / \mathrm{dl})$ & $51.7 \pm 6.0$ & $60.6 \pm 7.3$ & $62.0 \pm 7.3$ & $92.5 \pm 8.2^{* *}$ & $56.2 \pm 8.3^{*}$ & $67.0 \pm 6.8$ & $59.0 \pm 5.5$ \\
\hline
\end{tabular}

*Statistically significant $(p<0.05)$ differences compared to normal.

"Statistically significant differences between NR and R groups.

which was significantly lower than before therapy (240 $\pm 34 \mathrm{ng} / \mathrm{ml}, p<0.05)$. Analysis of hepcidin concentrations depending on the response to the treatment in the $\mathrm{R}$ group showed increased levels at week 4 of therapy, and then a decrease at week 48 to values significantly lower than those observed in the NR group (Fig. 1A). An increase in hepcidin levels after 4 weeks of treatment with a subsequent reduction of the infection was also observed in the $\mathrm{R}$ group of genotype $3 \mathrm{a}$ infected patients. However, the difference in relation to NR was not statistically significant (Fig. 1B). In our previous study [12] we observed that prohepcidin concentrations in the initial period of treatment were declining in both $\mathrm{R}$ and NR groups of patients infected with genotype $1 \mathrm{~b}$. After 4 weeks of therapy, prohepcidin concentrations in the $\mathrm{R}$ group showed a decrease, whereas in the NR group an increase to baseline level occurred, which resulted in statistically significant differences in 24 and 48 weeks of the therapy dependent on the final therapy response. As shown in Figure 2A, there was no effect of the treatment efficacy on the $\alpha$-1-antitrypsin concentration in patients infected with genotype $1 \mathrm{~b}$. In patients infected with genotype $3 \mathrm{a}$ a constant $\alpha$-1-antitrypsin level throughout the treatment period was observed in patients of the $R$ group, which was significantly lower than that observed in the NR group (Fig. 2B).

Baseline analyses showed a significant correlation between hepcidin and prohepcidin concentrations $(r=0.39, p<0.05)$ in all CHC patients, with the highest correlation coefficient observed in patients infected with genotype 1 who achieved SVR $(r=0.75, p<0.01)$. Moreover, there was a clear association in the $48^{\text {th }}$ week of treatment in genotype 1 infected patients $(r=0.98$, $p<0.001)$. Further analysis showed a significant positive correlation between serum hepcidin and ferritin, and a negative correlation between serum concentrations of prohepcidin and iron at baseline, but only in patients who achieved SVR (Table 3). Analysis of all subjects also showed a correlation between prohepcidin and $\alpha-1$-antitrypsin concentrations at the baseline $(r=0.38, p<0.05)$. 

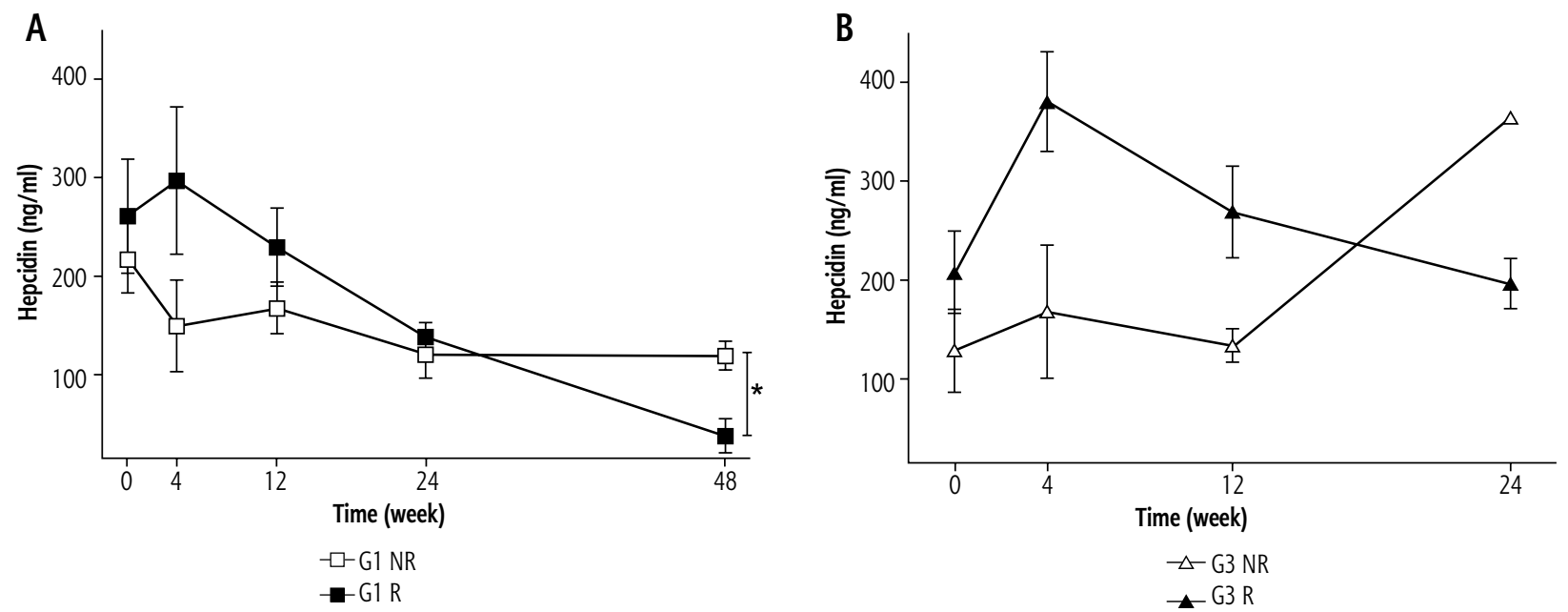

Fig. 1. Hepcidin concentrations during treatment of patients infected with genotype $1 \mathrm{~b}(\mathrm{~A})$ and genotype 3a hepatitis $\mathrm{C}$ virus (HCV) (B). Values given as mean \pm SE; ${ }^{*} p<0.05$
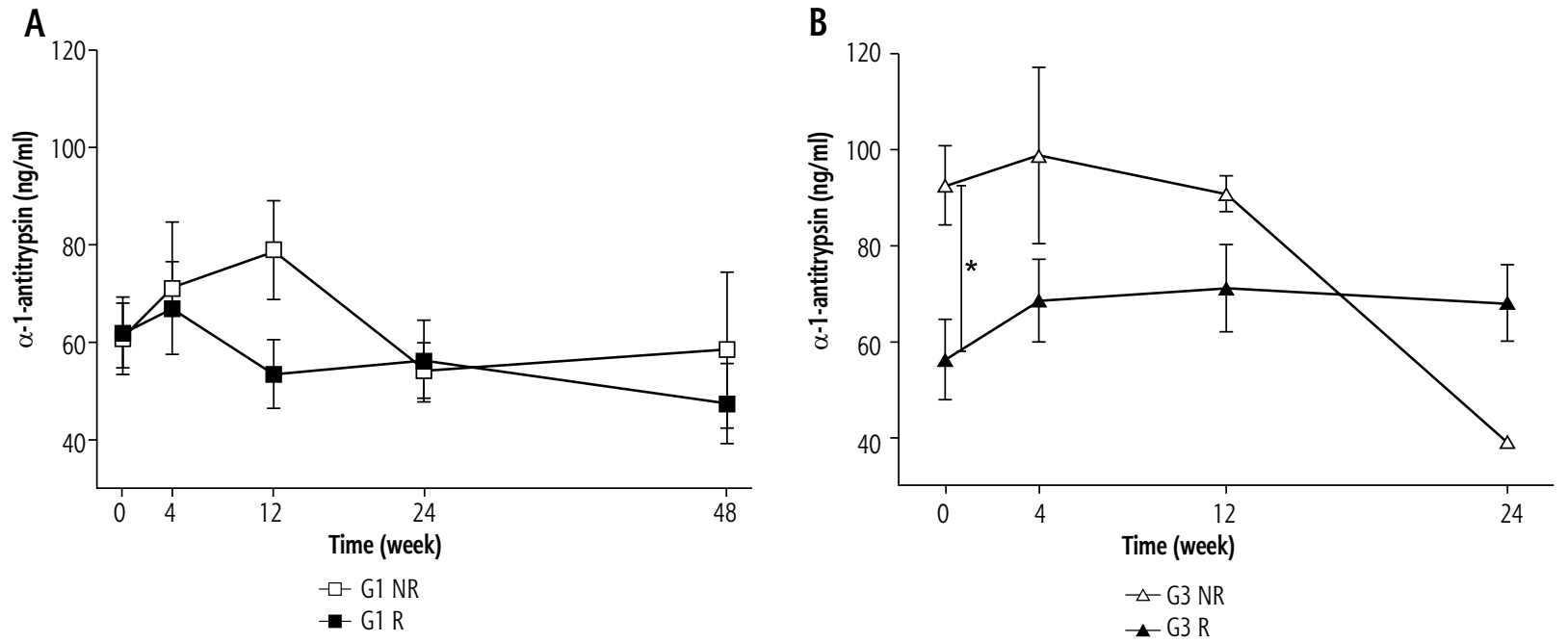

Fig. 2. $\alpha$-1-antitrypsin concentrations during treatment of patients infected with genotype $1 \mathrm{~b}(\mathbf{A})$ and genotype 3a hepatitis $\mathrm{C}$ virus (HCV) (B). Values given as mean \pm SE; $p<0.05$

\section{Discussion}

In this study we investigated the influence of PEG-INFa/RBV therapy on hepcidin, prohepcidin and $\alpha-1$-antitrypsin concentrations in sera of patients with chronic hepatitis $\mathrm{C}$. Chronic inflammation is frequently associated with liver tissue iron overload, as well as with anemia. Hepcidin is a key mediator of anemia of inflammation $[15,16]$. We have analyzed the relation between investigated factors and biochemical parameters of liver function as well as markers of iron metabolism.

Recent studies showed hepcidin deregulation in chronic hepatitis $C$ and suggested the pivotal role of this hormone in the pathogenesis of liver iron overload [17-19]. There is some evidence that hepatitis $C$ virus suppresses hepcidin expression in a reactive oxygen species-dependent manner through increased histone deacetylase activity [20, 21]. However, our study has shown that hepcidin concentrations were significantly increased in serum of both genotype $1 \mathrm{~b}$ and genotype 3a infected CHC patients measured before antiviral therapy as compared with healthy controls [12]. Moreover, we found a strong positive correlation of hepcidin levels with serum ferritin concentration, suggesting linkage between iron stores and hepcidin production, but importantly only in patients achieving an SVR. Ryan et al. [23] reported the strongest correlation between hepcidin and iron level changes during the first 24 hours of PEG-IFN $\alpha /$ RBV treatment in patients with the most significant decline of viral load, ultimately achieving an SVR. A positive association between liver hepcidin mRNA and serum ferritin, total iron score and 
Table 3. Correlation of baseline indicators expressed as $r$ value for all subjects with initial concentrations of prohepcidin, hepcidin and $\alpha$-1-antitrypsin with respect to response (R) or non-response (NR) to treatment

\begin{tabular}{lcccccc}
\hline & \multicolumn{2}{c}{ Prohepcidin } & \multicolumn{2}{c}{ Hepcidin } & \multicolumn{2}{c}{ Alpha-1-antitrypsin } \\
\cline { 2 - 7 } & NR & $\mathbf{R}$ & NR & $\mathbf{R}$ & NR & $\mathbf{R}$ \\
\hline HCV RNA & 0.15 & -0.32 & 0.47 & 0.01 & -0.04 & -0.08 \\
\hline ALT & 0.14 & 0.28 & -0.07 & 0.28 & 0.39 & 0.23 \\
\hline Bilirubin & 0.25 & 0.12 & 0.33 & 0.21 & 0.56 & 0.04 \\
\hline Fe & 0.11 & $-0.39^{*}$ & 0.23 & -0.12 & 0.02 & -0.39 \\
\hline TIBC & 0.18 & -0.19 & 0.04 & 0.10 & -0.05 & -0.21 \\
\hline UIBC & 0.5 & $-0.81^{*}$ & 0.40 & -0.61 & -0.80 & -0.54 \\
\hline Ferritin & -0.01 & 0.10 & 0.47 & $0.66^{*}$ & -0.01 & 0.08 \\
\hline Hemoglobin & 0.16 & -0.06 & 0.05 & 0.09 & 0.28 & 0.17 \\
\hline Stistilysifin
\end{tabular}

*Statistically significant correlation $(p<0.05)$.

hepatic iron accumulation in patients with $\mathrm{CHC}$ was found $[24,25]$. Sikorska et al. observed increased serum iron concentration correlating with hepcidin mRNA expression in the liver of CHC patients. Nevertheless, the authors did not observe a significant association of hepcidin mRNA expression with HCV viral load and efficacy of antiviral treatment [26]. However, due to posttranslational modification and regulation, biologic activity of mature 25-AA hepcidin peptide may not be fully reflected by mRNA-based assay. Pandur et al. [13] demonstrated that the protease inhibitor $\alpha-1$-antitrypsin robustly interacts with preprohepcidin as well as with prohepcidin in the cell and in the serum, playing a role in protection from cleavage by furin and thus hormone maturation. Furthermore, $\alpha$-1-antitrypsin mRNA in cells was over 2-fold increased under preprohepcidin overexpression [13]. Prohepcidin can bind to and transcriptionally regulate the expression of HAMP in hepatocytes, but only the non- $\alpha-1$-antitrypsin-bound prohepcidin affects the expression of its own gene [27]. In our study analysis of correlations at baseline showed a significant association between hepcidin and prohepcidin concentrations in the group of $\mathrm{CHC}$ patients, with the highest correlation coefficient observed in genotype 1 patients who achieved SVR. In particular, the strongest association was noted in the $48^{\text {th }}$ week of treatment in genotype 1 . Of note, we also observed a positive correlation between prohepcidin and $\alpha$-1-antitrypsin concentrations measured before therapy, although the baseline $\alpha$-1-antitrypsin concentrations do not differ significantly from control group values. This may indicate the existence of regulatory interdependence between prohepcidin and $\alpha$-1-antitrypsin, which ultimately may affect hepcidin level in the blood of $\mathrm{CHC}$ patients. The role of $\alpha-1$-antitrypsin was confirmed by data showing an association between inherited muta- tions within the $\alpha$-1-antitrypsin gene and increased iron accumulation [28]. A study by Ghio et al. [29] showed significant correlations between both plasma ferritin and iron with $\alpha$-1-antitrypsin levels.

Bartolomei et al. [14] demonstrated hepcidin upregulation at the mRNA level by IFN- $\alpha$ through the STAT3 transcription factor. The authors showed that hepcidin is the only iron-related gene modulated by IFN- $\alpha$ treatment of hepatocytes in vitro [14]. In accordance with our results, Ryan et al. [23] reported fast STAT3 signaling-mediated hepcidin induction in $\mathrm{CHC}$ patients following the initiation of PEG-IFNa treatment. In our research hepcidin levels gradually declined during treatment in genotype $1 \mathrm{~b}$, reaching significantly lower values at the treatment termination than before therapy. Whereas in the responder (R) group serum hepcidin concentration increased at week 4 and tended to decrease to reach by the end of treatment values similar to those in the control group, in the non-responder (NR) group it showed a decreased level at week 4 maintained during the following weeks of treatment. This may also reflect the link between differential activation of interferon inducible genes and iron homeostasis during therapy with PEG-IFNo. Of note, recently Liu et al. [30] found that hepcidin has direct antiviral activity against HCV replication in vitro through activation of STAT3. We observed that hepcidin concentration in genotype $1 \mathrm{~b}$ differed significantly between R and NR groups at week 48 of the treatment. We observed a similar trend in hepcidin concentrations in both $\mathrm{R}$ and NR groups of genotype $3 \mathrm{a}$, although there was no statistically significant difference between groups by the end of the therapy, perhaps due to the low number of cases in the NR group at this time point.

A weakness of our study might be the absence of measurement at 24 weeks after the end of the antiviral 
therapy when there is no potential impact of ribavirin-induced hemolytic anemia [31] on complex hepcidin production. Interestingly, Fujita et al. [22] observed a significantly increased serum hepcidin level 24 weeks after successful HCV eradication compared with a relatively low concentration before therapy.

We have presented longitudinal analysis of serum hepcidin and $\alpha$-1-antitrypsin concentrations during the antiviral treatment in chronic HCV infection. Differential dynamics of hepcidin during PEG-IFNa/ RBV therapy in responders and non-responders may indicate the direct influence of viral eradication on iron homeostasis. $\alpha$-1-antitrypsin serum concentration was not affected by the antiviral treatment efficacy. Importantly, successful therapy was associated with restoration of serum hepcidin concentration to values similar to the control group, which may contribute to reversal of HCV-related iron metabolism dysfunction.

\section{Disclosure}

\section{Authors report no conflict of interest.}

\section{References}

1. Boucher E, Bourienne A, Adams P, et al. Liver iron concentration and distribution in chronic hepatitis $\mathrm{C}$ before and after interferon treatment. Gut 1997; 41: 115-120.

2. Bonkovsky HL. Iron as a comorbid factor in chronic viral hepatitis. Am J Gastroenterol 2002; 97: 1-4.

3. Franchini M, Targher G, Capra F, et al. The effect of iron depletion on chronic hepatitis $C$ virus infection. Hepatol Int 2008; 2: 335-340.

4. She $\mathrm{H}$, Xiong $\mathrm{S}$, Lin $\mathrm{M}$, et al. Iron activates NF-kappaB in Kupffer cells. Am J Physiol Gastrointest Liver Physiol 2002; 283: G719-726.

5. Gardi C, Arezzini B, Fortino V, et al. Effect of free iron on collagen synthesis, cell proliferation and MMP-2 expression in rat hepatic stellate cells. Biochem Pharmacol 2002; 64: 1139-1145.

6. Park $\mathrm{CH}$, Valore E V, Waring AJ, et al. Hepcidin, a urinary antimicrobial peptide synthesized in the liver. J Biol Chem 2001; 276: 7806-7810.

7. Pigeon C, Ilyin G, Courselaud B, et al. A new mouse liver-specific gene, encoding a protein homologous to human antimicrobial peptide hepcidin, is overexpressed during iron overload. J Biol Chem 2001; 276: 7811-7819.

8. Nicolas G, Chauvet C, Viatte L, et al. The gene encoding the iron regulatory peptide hepcidin is regulated by anemia, hypoxia, and inflammation. J Clin Invest 2002; 110: 1037-1044.

9. Nicolas G, Bennoun M, Devaux I, et al. Lack of hepcidin gene expression and severe tissue iron overload in upstream stimulatory factor 2 (USF2) knockout mice. Proc Natl Acad Sci U S A 2001; 98: 8780-8785

10. Kulaksiz H, Gehrke SG, Janetzko A, et al. Pro-hepcidin: expression and cell specific localisation in the liver and its regulation in hereditary haemochromatosis, chronic renal insufficiency, and renal anaemia. Gut 2004; 53: 735-743.

11. Valore Ganz, Valore E V, Ganz T. Posttranslational processing of hepcidin in human hepatocytes is mediated by the prohormone convertase furin. Blood Cells Mol Dis 2008; 40: 132-138.
12. Jaroszewicz J, Rogalska M, Flisiak I, et al. Successful antiviral therapy is associated with a decrease of serum prohepcidin in chronic hepatitis C. World J Gastroenterol 2010; 16: 1747-1752.

13. Pandur E, Nagy J, Poór VS, et al. Alpha-1 antitrypsin binds preprohepcidin intracellularly and prohepcidin in the serum. FEBS J 2009; 276: 2012-2021.

14. Bartolomei G, Cevik RE, Marcello A. Modulation of hepatitis $\mathrm{C}$ virus replication by iron and hepcidin in Huh7 hepatocytes. J Gen Virol 2011; 92: 2072-2081.

15. Weiss G. Iron metabolism in the anemia of chronic disease. Biochim Biophys Acta 2009; 1790: 682-693.

16. Kartikasari AE, Roelofs R, Schaeps RM, et al. Secretion of bioactive hepcidin- 25 by liver cells correlates with its gene transcription and points towards synergism between iron and inflammation signaling pathways. Biochim Biophys Acta 2008; 1784: 2029-2037.

17. Fujita N, Sugimoto R, Ma N, et al. Comparison of hepatic oxidative DNA damage in patients with chronic hepatitis B and C. J Viral Hepat 2008; 15: 498-507.

18. Fujita N, Sugimoto R, Urawa N, et al. Influence of phlebotomy on iron-related gene expression levels in the livers of patients with chronic hepatitis C. J Gastroenterol 2007; 42: 326-327.

19. Nagashima M, Kudo M, Chung H, et al. Regulatory failure of serum prohepcidin levels in patients with hepatitis C. Hepatol Res 2006; 36: 288-293.

20. Nishina S, Hino K, Korenaga M, et al. Hepatitis C virus-induced reactive oxygen species raise hepatic iron level in mice by reducing hepcidin transcription. Gastroenterology 2008; 134: 226-238.

21. Miura K. Hepatitis C virus-induced oxidative stress suppresses hepcidin expression through increased histone deacetylase activity. Hepatology 2008; 48: 1420-1429.

22. Fujita N, Sugimoto R, Motonishi S, et al. Patients with chronic hepatitis $\mathrm{C}$ achieving a sustained virological response to peginterferon and ribavirin therapy recover from impaired hepcidin secretion. J Hepatol 2008; 49: 702-710.

23. Ryan JD, Altamura S, Devitt E, et al. Pegylated interferon- $\alpha$ induced hypoferremia is associated with the immediate response to treatment in hepatitis C. Hepatology 2012; 56: 492-500.

24. Trinder D, Ayonrinde OT, Olynyk JK. HCV, iron, and oxidative stress: the new choreography of hepcidin. Gastroenterology 2008; 134: 348-351.

25. Fujita N, Horiike S, Sugimoto R, et al. Hepatic oxidative DNA damage correlates with iron overload in chronic hepatitis $\mathrm{C}$ patients. Free Radic Biol Med 2007; 42: 353-362.

26. Sikorska K, Romanowski T, Stalke P, et al. Association of hepcidin mRNA expression with hepatocyte iron accumulation and effects of antiviral therapy in chronic hepatitis $\mathrm{C}$ infection. Hepat Mon 2014; 14: e21184.

27. Pandur E, Sipos K, Grama L, et al. Prohepcidin binds to the HAMP promoter and autoregulates its own expression. Biochem J 2013; 451: 301-311.

28. Valenti L, Dongiovanni P, Piperno A, et al. Alpha 1-antitrypsin mutations in NAFLD: high prevalence and association with altered iron metabolism but not with liver damage. Hepatology 2006; 44: 857-864.

29. Ghio AJ, Soukup JM, Richards JH, et al. Deficiency of $\alpha$-1-antitrypsin influences systemic iron homeostasis. Int J Chron Obs Pulmon Dis 2013; 8: 45-51.

30. Liu H, Trinh $\mathrm{T}$ Le, Dong $\mathrm{H}$, et al. Iron regulator hepcidin exhibits antiviral activity against hepatitis C virus. PLoS One 2012; 7: e46631.

31. Takaki S, Tsubota A, Hosaka T, et al. Factors contributing to ribavirin dose reduction due to anemia during interferon alfa2b and ribavirin combination therapy for chronic hepatitis C. J Gastroenterol 2004; 39: 668-673. 